\title{
Price Versus Production Postponement: Capacity and Competition
}

\author{
Jan A. Van Mieghem • Maqbool Dada \\ Kellogg Graduate School of Management, Northwestern University, Evanston, Illinois 60208 \\ Krannert Graduate School of Management, Purdue University, West Lafayette, Indiana 47907
}

\begin{abstract}
$\mathrm{T}$ his article presents a comparative analysis of possible postponement strategies in a two-stage decision model where firms make three decisions: capacity investment, production (inventory) quantity, and price. Typically, investments are made while the demand curve is uncertain. The strategies differ in the timing of the operational decisions relative to the realization of uncertainty.

We show how competition, uncertainty, and the timing of operational decisions influence the strategic investment decision of the firm and its value. In contrast to production postponement, price postponement makes the investment and production (inventory) decisions relatively insensitive to uncertainty. This suggests that managers can make optimal capacity decisions by deterministic reasoning if they have some price flexibility. Under price postponement, additional postponement of production has relatively small incremental value. Therefore, it may be worthwhile to consider flexible ex-post pricing before production postponement reengineering. While more postponement increases firm value, it is counterintuitive that this also makes the optimal capacity decision more sensitive to uncertainty. We highlight the different impact of more timely information, which leads to higher investment and inventories, and of reduced demand uncertainty, which decreases investment and inventories. Our analysis suggests appropriateness conditions for simple make-to-stock and make-to-order strategies. We also present technical sufficiency and uniqueness conditions. Under price postponement, these results extend to oligopolistic and perfect competition for which pure equilibria are derived. Interestingly, the relative value of operational postponement techniques seems to increase as the industry becomes more competitive.

(Capacity; Investment; Pricing; Competition; Production; Inventory; Strategy; Demand Uncertainty)
\end{abstract}

\section{Introduction}

This article presents a comprehensive analysis of postponement strategies in a two-stage decision model in which firms make three decisions: capacity investment, production (inventory) quantity, and price. The following examples motivate the strategies to be examined.

1. Consider a publisher who is about to release a new book. Before sales can be observed, the publisher announces a price and determines how many copies to print. Unsold books are destroyed.

2. Consider a manufacturer introducing a new product. After investing in capacity, the firm announces a price. Then, in response to the revealed market demand, an appropriate production quantity is set.

3. Consider a traditional automobile dealer who must decide how many cars to buy and hold on its 
premises before market demand is known. Then, the selling price is "negotiated" with each customer.

4. Consider the marketing of fresh produce by a farm cooperative. Capacity is determined in advance of the season. Then the crop is harvested. Depending on the yield and market conditions, either all product is brought to the market, which sets the price, or a portion of the harvest is destroyed to influence the market-clearing price.

These four examples illustrate a wide range of operational strategies seen in the retail and manufacturing sectors of the economy. They highlight the three essential decisions that are the focus of this article. The strategic capacity investment decision is made under uncertainty in all examples. Recent practices of tying guarantees in supply contracts to the ex-ante capacity decision make this type of investment even more significant. ${ }^{1}$ The relative timing of the more tactical pricing and production decisions differs however. We refer to a strategy under which all three decisions are made while demand is uncertain, as in Example 1, as no postponement. The ability to set the production quantity after demand uncertainty is resolved, as in Example 2, is a form of production postponement (and a simplified model of make-toorder). Similarly, the ability to defer the pricing decision until demand uncertainty is resolved, as in Examples 3 and 4 , is a form of price postponement (and a simplified model of make-to-stock with ex-post pricing flexibility). While much has been written in the recent operations literature on production postponement (see below), price postponement and its value and impact compared to production postponement has received little attention.

\section{Summary}

The intent of this article is to provide insight into the economic and operational value of price postponement versus production postponement strategies by analyzing a relatively simple two-stage stochastic investment-production-pricing model, adapted from the

\footnotetext{
${ }^{1}$ When installing production capacity for its Smart car, "DaimlerChrysler guaranteed many parts suppliers an annual production volume of about 100,000 units to get them to set up near the Smart factory in Hambach, France" (Andrews 1999, p. C8).
}

industrial organization literature in economics. Section 2 introduces the monopoly version of the model and partially ranks the six possible postponement strategies that arise from changing the timing of the resolution of demand uncertainty. The first four strategies correspond to the examples above, while Strategy 5 assumes that both price and production can be postponed. Strategy 6, where all three decisions are postponed and hence made under perfect information, yields a convenient upper bound on the value of the other postponement strategies. Our analysis suggests appropriateness conditions for simple make-tostock and make-to-order strategies.

Section 3 shows an equivalence between production postponement and no postponement (Strategies 2 and $1)$, which both involve ex-ante price setting. We present technical sufficiency conditions and show that optimal capacity, price, and firm value are not monotone in variability and they can be above or below their deterministic counterparts. Section 4 focuses on price postponement strategies, which are more amenable to analysis than their ex-ante price setting counterparts. Explicit unique solutions and comparisons are presented for a wide class of uncertainty distributions. This leads to several managerial insights. First, price postponement strategies make the capacity investment and production (inventory) decisions relatively insensitive to uncertainty. In contrast, the investment under production postponement always is sensitive to uncertainty so that price postponement seems to result in a more effective hedge in the context of our model. This also suggests that managers can make good capacity and production decisions by deterministic reasoning if levels of demand variability are moderate and the firm has ex-post price flexibility. Second, this insensitivity result directly shows that if price postponement is possible, additional production postponement has relatively small incremental value, especially under low to moderate demand variability. Hence, before devising production postponement reengineering techniques it may be worthwhile to consider flexible ex-post pricing, which typically falls under marketing's responsibilities. Third, capacity, production and inventory, and firm value are weakly increasing in variability under price postponement. 
While the capacity and inventory response may be explained in terms of usual safety stock reasoning, we believe that this response and the increased firm value simply reflect the increased option value of ex-post pricing flexibility, which is absent in traditional inventory models with constant price. At the same time, we demonstrate that additional postponement-or, equivalently, better information in the sense of earlier resolution and observation of uncertainty-also increases capacity, production and inventory, and firm value. This is consistent with the recent finding of Anand (1999) that inventory and better information (in the sense of a less noisy observation of demand uncertainty) can be complements in a multiperiod model. Perhaps counterintuitive at first sight, this simply highlights the different impact of more timely information, which justifies higher investment to better exploit ex-post flexibility, and of reduced demand variability, which results in lower safety-stock investment.

Section 5 incorporates competition by introducing an arbitrary number of competitors in the gametheoretic analysis of price postponement strategies. In contrast to production postponement, we show that a subgame-perfect pure strategy equilibrium exists and we present technical conditions on the hazard rate that guarantee uniqueness. We find that as the number of competitors increases, the uncertainty-insensitivity result remains but is more muted. Interestingly, however, the relative value to the firms of additional production postponement seems to increase with competition. Section 6 closes with some concluding remarks. Finally, the Appendix contains some technical proofs.

\section{Relationship to the Literature}

Inspired by the practices of Benetton (Signorelli and Heskett 1984), there has been a growing interest in the formal study of production postponement and its operational trade-offs. The work of Lee and coauthors, well summarized by Lee and Tang (1998), introduces the notion of operations reversal as a reengineering paradigm for production postponement and accompanying variability reduction. Delaying the point of differentiation in a multiproduct firm results in increased flexibility and in lower safety stock of com- mon upstream inputs. This results from statistical pooling benefits and improved forecasting errors due to reduced forecast horizons (Anupindi et al. 1999). These models can be used to determine when production postponement would be viable. As in many operations models, price and demand are often considered exogenous so that such models may underestimate the benefit of production postponement. In contrast, we analyze the impact of production postponement on price and demand and compare it with price postponement by tracing the impact on capacity investment and firm value.

The monopoly analysis also relates to the considerable literature that considers the interaction of pricing, production, and capacity decisions (often inventory investment plays an analogous constraining role to that of capacity investment). Whitin's model (1955), analyzed by Mills (1959), appears to have been the first to consider the simultaneous choice of inventory and prices, equivalent to our no postponement strategy; an integrative review is provided by Petruzzi and Dada (1999). We contribute to this literature by presenting new sufficiency conditions on the hazard rate, by analyzing the impact of zero demand states and by considering price and production postponement. In particular, the monopoly model of Padmanabhan and Png (1997) is a special case of the price postponement monopoly model of $\S 3$ for a binary demand distribution. Anand and Mendelson (1998) study the increased flexibility and pooling benefits of delayed production in a multiproduct supply chain that is endowed with a noisy information system on the binary demand distribution. In studying contracting (rather than competition) in a supply chain, Ha (1997) also solves a special case of our monopoly model.

The game-theoretical analysis of competition is fraught with difficulty because the seminal equivalence result of Kreps and Scheinkman (1983) - that price and production postponement strategies can be equivalent in a duopoly model with deterministic demand curve-does not hold when demand is uncertain. In fact, pure Nash equilibria for production postponement strategies do not even exist for the stochastic game (Hviid 1991). One way to overcome this technical difficulty with the competitive produc- 
tion postponement model is to assume exogenous prices, as in recent literature on competition in operations. Lipmann and McCardle (1997) and Parlar (1988) study competitive inventory decisions, which in their most simple form directly correspond to capacity decisions, by analyzing a competitive newsvendor model. To analyze subcontracting and outsourcing, Van Mieghem (1999) studies the competitive capacity and production decisions of a contractor and subcontractor. Because prices are exogenous in these articles, the effect of tactical price or production competition on the investment decisions cannot be analyzed. A second approach is to impose institutional structures that make prices "sticky" as applied by Deneckere et al. (1996, 1997), Deneckere and Peck (1995), and Peck (1996) and Butz (1997). Another alternative is to consider alternative formulations of our duopoly model. Gal-Or (1987), Hviid (1990), and Bashyam (1996) change the timing of the players' relative decisions and consider sequential pricing games to study firstmover advantage. Gal-Or, followed by Bashyam, both add private information to the investment decision. Arthur (1997) introduces product differentiation. In contrast to these papers, our emphasis is on studying price postponement, a strategy that has received limited attention in the literature, and on the impact of the intensity of competition and uncertainty on the capacity decision.

\section{Monopoly Model: Six Postponement Strategies}

Consider a monopolist who makes three decisions. First, the firm makes a strategic investment decision in production capacity $K$, followed by two tactical (operational) decisions to set price $p$ and production quantity $q \leq K$, constrained by the earlier capacity decision. The monopolist faces an uncertain market demand curve. Obviously, the three decisions will depend on the available information set, which in this case depends on when the monopolist observes actual demand relative to when each decision has to be made. Because investment must precede price and production setting, our comprehensive analysis involves the study of six strategies, each specifying which decision is postponed until after uncertainty is realized. Before doing so, let us discuss the model features that are common to all six strategies.

Cost Parameters. The monopolist's total cost $C$ is comprised of three parts. First, a capacity decision $K$ $\geq 0$ incurs an investment $\operatorname{cost} C_{K}(K)=c_{K} K$. (All our results directly extend to convex investment cost functions $C_{K}(K)$.) Second, the production quantity decision $q \leq K$ involves a constant marginal production $\operatorname{cost} c_{q}$. Third, $c_{h}$ specifies the constant marginal inventory holding cost rate of ex-ante production.

Revenue Parameters. To specify revenues $R$, it is useful to differentiate the actual sales quantity $s$ from the production quantity $q$ and the demand $D$. At unit price $p$, revenues simply are $R=p s$. Clearly, sales cannot exceed demand nor production:

$$
s \leq \min (q, D) .
$$

Uncertainty in the market demand $D$ is modeled by a random variable $\epsilon$, also called a "shock." Specifically, the (inverse) demand curve is assumed to be linear and we can always scale units such that

$$
p=\epsilon-D \geq 0 .
$$

The random variable $\epsilon$ has mean 1 and perturbs the deterministic demand curve $p=1-D$ by representing uncertainty in the intercept or market size or willingness-to-pay. Thus, $\epsilon$ is nonnegative and to avoid technicalities we will assume that its probability measure $P$ has a distribution $F(\epsilon)$ with continuous density $f(\epsilon)$ over $\mathbb{R}_{+}$and standard deviation $\sigma$. Let $\bar{F}$ $=1-F$ denote the tail distribution and $h=f / \bar{F}$ the hazard or failure rate. For our analysis, it will be useful to partition the state-space for $\epsilon$ as follows: $\mathbb{R}_{+}$ $=\Omega_{0} \cup \Omega_{1} \cup \Omega_{2}$, or $\Omega_{012}$ for short, where

$$
\begin{gathered}
\Omega_{0}(p)=[0, p), \quad \Omega_{1}(p, K)=[p, p+K) \text { and } \\
\Omega_{2}(p, K)=[p+K,+\infty) .
\end{gathered}
$$

The three domains represent three possible outcomes. Domain $\Omega_{0}$ represents the undesired outcome where the willingness-to-pay is so low, or equivalently the price is so high, that there is no demand at the announced price $p: D(p)=0$. In domain $\Omega_{1}$, the monopolist has sufficient capacity to satisfy demand: $D(p)<K$. Finally, in domain $\Omega_{2}$ market demand 
exceeds capacity and some potential sales are lost: $D(p) \geq K$.

Objective. We assume that the monopolist is riskneutral and maximizes expected firm value $V$, which equals expected revenues minus expected cost:

$$
V=\mathrm{E}[R-C],
$$

where E denotes the expectation operator. To specify $V$ in terms of the model parameters and to determine the optimal decisions of investment $K$, production $q$, and price $p$ we must specify their timing relative to the observation of $\epsilon$. This directly leads us to define the following six strategies.

\subsection{Strategy 1: No Postponement}

Under a no postponement strategy, the firm must make all three decisions $K, q$, and $p$ in Stage 1, before uncertainty is resolved. Clearly, it is suboptimal to invest in excess capacity so that $K=q$. Production is made to stock and the firm incurs inventory holding costs. ${ }^{2}$ All costs are incurred in the first stage: $C=\left(c_{K}\right.$ $\left.+c_{q}+c_{h}\right) K$. In the second stage, after demand uncertainty is resolved, all costs are sunk and firm value is maximized by maximizing revenues and thus sales. From (1) and (2), it follows that

$$
s=\min (q, D(p, \epsilon))=\min \left(K,(\epsilon-p)^{+}\right) .
$$

Consequently, if demand is low $\left(\epsilon \in \Omega_{0+1}(p+K)\right)$, some production is wasted, while some high demand may be left unfilled $\left(\epsilon \in \Omega_{2}(p+K)\right)$. Hence, expected revenues $p$ Es lead to firm value (subscripts specify the strategy):

$$
\begin{aligned}
& V_{1}(K, p)=-\left(c_{K}+c_{q}+c_{h}\right) K+p \operatorname{Emin}\left(K,(\epsilon-p)^{+}\right) \\
& =-\left(c_{K}+c_{q}+c_{h}\right) K+\int_{\Omega_{1}} p(\epsilon-p) d P+\int_{\Omega_{2}} p K d P .
\end{aligned}
$$

\subsection{Strategy 2: Production Postponement}

Under production postponement, the firm must set $K$ and $p$ before uncertainty is resolved, but it can post-

\footnotetext{
${ }^{2}$ For simplicity, we assume a unit time lag between Stages 1 and 2 . To investigate different time lags $\Delta t$ one would use $c_{h} \Delta t$ instead of $c_{h}$.
}

pone its production. Economists might say that the firm acts in price setting mode. In the second stage we observe $\epsilon$ and thus also the demand $D=(\epsilon-p)^{+}$. Consequently, we will produce only as much as we can sell (one will price above production cost, $p>c_{q}$ and produce up to capacity limits: $q=s \leq K)$ :

$$
q=s=\min \left(K,(\epsilon-p)^{+}\right),
$$

with firm value:

$$
\begin{aligned}
V_{2}(K, p)= & -c_{K} K+\left(p-c_{q}\right) \operatorname{E} \min \left(K,(\epsilon-p)^{+}\right) \\
= & -c_{K} K+\int_{\Omega_{1}}\left(p-c_{q}\right)(\epsilon-p) d P \\
& +\int_{\Omega_{2}}\left(p-c_{q}\right) K d P .
\end{aligned}
$$

2.3. Strategy 3: Price Postponement with Clearance Under price postponement with clearance, the firm must set $K$ and $q$ before uncertainty is resolved and all output $q$ is brought to the market. This is known as quantity setting in economics. Clearly, there is no need for excess capacity and $K=q$. In the second stage we observe $\epsilon$ and the market mechanism sets a price $p$ that "clears the market," i.e., sells all output, possibly at zero price (if maximum demand at zero price (max $D=\epsilon$ ) is less than output). We refer to this phenomenon as clearance sales:

$$
s=q=K \text { and thus } p=(\epsilon-K)^{+} .
$$

The resulting firm value becomes univariate:

$$
\begin{aligned}
V_{3}(K) & =-\left(c_{K}+c_{q}+c_{h}\right) K+K \mathrm{E}(\epsilon-K)^{+} \\
& =-\left(c_{K}+c_{q}+c_{h}\right) K+\int_{\Omega_{1+2}(K)} K(\epsilon-K) d P .
\end{aligned}
$$

The market clearing price, however, is not necessarily the optimal price. When maximum demand is less than output $\left(\epsilon \in \Omega_{0}(K)\right.$ ), no revenue is generated and it would be better to price higher and not sell all output. This leads us to Strategy 4. 


\subsection{Strategy 4: Price Postponement with Hold- Back}

Under "refined" price postponement, the firm must set $K$ and $q$ before uncertainty is resolved; but it has some pricing power in the second stage. As before, we have $K=q$, but after observing $\epsilon$ we set an optimal price. Under low demand conditions, it is better to hold back some stock (e.g., destroy it) and sell only a restricted quantity $s<q$ at a higher price than to sell all stock at a lower market clearing price as in Strategy 3. The optimal ex-post price $p=\epsilon-s$ maximizes revenues $s(\epsilon-s)$, where $s \leq q=K$, so that

$$
s=\min \left(\frac{\epsilon}{2}, K\right) \text { and } p=\max \left(\frac{\epsilon}{2}, \epsilon-K\right) .
$$

Thus, under poor market conditions $\left(\epsilon \in \Omega_{0}(2 K)\right)$ we choose to hold back some stock and sell only $\epsilon / 2$, which is less than production or stock $q=K$. Again, the value function becomes univariate:

$$
\begin{aligned}
V_{4}(K)= & -\left(c_{K}+c_{q}+c_{h}\right) K+E \min \left(\frac{\epsilon^{2}}{4}, K(\epsilon-K)^{+}\right) \\
= & -\left(c_{K}+c_{q}+c_{h}\right) K+\int_{\Omega_{0}(2 K)} \frac{1}{4} \epsilon^{2} d P \\
& +\int_{\Omega_{1+2}(K)} K(\epsilon-K) d P .
\end{aligned}
$$

To complete our study of all possible postponement strategies, we present the two remaining strategies: Postpone price and production (Strategy 5) and also postpone capacity (Strategy 6).

\subsection{Strategy 5: Price and Production Postponement}

In this case only $K$ must be selected before uncertainty is resolved. In the second stage we observe $\epsilon$ and will price optimally as in Strategy 4 but now we also postpone production. Hence, we only produce the sold quantity $(q=s)$ if the price $p=\epsilon-s$ exceeds the marginal production cost (which was sunk in Strategy 4$)$ to maximize operating profits $s(\epsilon$ $-s-c_{q}$ ) so that

$$
\begin{gathered}
s=\min \left(\frac{1}{2}\left(\epsilon-c_{q}\right)^{+}, K\right) \quad \text { and } \\
p=\max \left(\frac{1}{2}\left(\epsilon+c_{q}\right), \epsilon-K\right) .
\end{gathered}
$$

Thus, we do not produce under dire market conditions $\left(\epsilon \in \Omega_{0}\left(c_{q}\right)\right)$ while we produce and sell less than full capacity under poor market demand $\left(\epsilon \in \Omega_{1}\left(c_{q}\right.\right.$, $2 K)$ ). The value function becomes:

$$
\begin{aligned}
V_{5}(K)= & -c_{K} K+\int_{\Omega_{1}\left(c_{q}, 2 K\right)} \frac{1}{4}\left(\epsilon-c_{q}\right)^{2} d P \\
& +\int_{\Omega_{2}\left(c_{q}, 2 K\right)} K\left(\epsilon-K-c_{q}\right) d P .
\end{aligned}
$$

\subsection{Strategy 6: Full Postponement}

Finally, a full postponement strategy captures the (unlikely) event that all decisions can be postponed until $\epsilon$ is observed. Thus, all decisions are made under perfect information and the firm now faces a deterministic decision problem. It can eliminate all shortages, wasted production, excess capacity and holding costs. Hence:

$$
q=K=s=\epsilon-p
$$

and capacity maximizes $V_{6}(\epsilon)=(\epsilon-K) K-\left(c_{K}\right.$ $\left.+c_{q}\right) K$, with solution:

$$
\begin{gathered}
K(\epsilon)=\frac{1}{2}\left(\epsilon-c_{K}-c_{q}\right)^{+} \text {and } \\
V_{6}(\epsilon)=\frac{1}{4}\left(\epsilon-c_{K}-c_{q}\right)^{+2}
\end{gathered}
$$

and expected value:

$$
V_{6}=\frac{1}{4} \mathrm{E}\left(\epsilon-c_{K}-c_{q}\right)^{+2} \leq \frac{\left(1-c_{K}-c_{q}\right)^{2}+\sigma^{2}}{4} .
$$

\subsection{Dominant Strategies and the Value of Information}

Our detailed description of the various postponement strategies enhances intuition and directly allows a partial ranking of the value of the strategies. Indeed, postponing a decision until after uncertainty is realized yields a perfect information set when making that decision. Postponement then directly induces the following weak dominance on optimal strategies: 
Proposition 1. The optimal values of the different postponement strategies rank as:

$$
\left.\begin{array}{r}
V_{1} \leq\left(V_{2}, V_{4}\right) \\
V_{3} \leq V_{4}
\end{array}\right\} \leq V_{5} \leq V_{6} \leq \frac{\left(1-c_{K}-c_{q}\right)^{2}+\sigma^{2}}{4} .
$$

Proof. Clearly, full postponement dominates all other strategies and it gives a simple upper bound to performance that only depends on the first two moments of the demand distribution. The relative ranking of Strategies 4 and 5 is also obvious: Postponing production in addition to price (Strategy 5) dominates postponing price only (Strategy 4) through elimination of holding costs and suitable make-to-order production so that no hold-back is necessary, thereby reducing production costs. By postponing pricing in addition to production, Strategy 5 also dominates the production postponement Strategy 2. The production postponement Strategy 2 weakly dominates Strategy 1 by saving on production costs under low demand scenarios and always on inventory holding costs:

$$
V_{2}(K, p)-V_{1}(K, p)=c_{q} \mathrm{E}(\epsilon-p)^{+}+c_{h} K \geq 0 .
$$

Similarly, the price postponement with hold-back Strategy 4 weakly dominates Strategy 1 through an optimal state-dependent price choice. It also dominates Strategy 3 because the market clearing price is not always the optimal price.

The relative ranking of the production postponement Strategy 2 and the refined price postponement Strategy 4, however, is unclear. Similarly, the ranking of the no postponement Strategy 1 versus the simple price postponement Strategy 3 is unclear because Strategy 3 does not use optimal decisions (rather, it uses market-clearing pricing). If, however, production is costless $\left(c_{q}=c_{h}=0\right)$, production postponement does not yield any savings and (17) yields:

$$
V_{1}=V_{2} \leq V_{4} \leq V_{5} \leq V_{6} .
$$

In general, however, the presence of production and holding costs may break this ranking (while the incorporation of shortage costs would strengthen it). To gain more insight into the optimal investment, price, and production/inventory decisions, we now proceed to an analysis of the two main strategies in the next two sections. This will allow us to partially rank optimal investment and production/inventory levels under the various strategies and highlight their dependence on variability. While we will be able to clarify the value ranking under moderate uncertainty, a general definitive ranking of $V_{2}$ versus $V_{4}$ will remain elusive. Equation (17) suggests that the value of production postponement $V_{2}-V_{1}$ rises as variability and marginal production and holding $\operatorname{cost} c_{q}$ and $c_{h}$ rise. Given that price postponement Strategy 4 dominates Strategy 1, this implies that Strategy 4 will dominate 2 for low levels of variability and low marginal production and holding costs. This suggests that simple make-to-stock with price-flexibility strategies are preferred over simple make-to-order strategies if variability levels and marginal production and holding costs are low. In general, however, their relative ranking reflects the trade-off between saving on production and holding cost versus benefitting from price flexibility. The optimal trade-off will depend on the parameters $c_{q}$ and $c_{h}$ versus the variability in $\epsilon$ (Proposition 2 will show that the translated distribution comes into play). Finally, $\$ 5$ extends our monopoly model and analysis to investigate the value of postponement under competition.

\section{Analysis of Production and No Postponement Strategies 2 and 1}

While it is evident that production postponement dominates no postponement by saving on production costs under low demand scenarios and always on inventory holding costs, it is analytically equivalent to no postponement:

Proposition 2. Strategies 1 and 2 are equivalent in the sense that the optimal positive decisions $K_{2}$ and $p_{2}$ for Strategy 2 can be obtained from solving Strategy 1 with modified parameters (and vice versa):

$$
K_{2}=K_{1}^{*} \text { and } p_{2}=c_{q}+p_{1}^{*},
$$

where $K_{1}^{*}$ and $p_{1}^{*}$ are the optimal decisions under Strategy 1 , calculated using distribution $f^{*}(\epsilon)=f\left(\epsilon+c_{q}\right)$ and zero marginal production and holding cost $\left(c_{q}^{*}=c_{h}^{*}=0\right)$.

Production postponement is equivalent to a no postponement Strategy 1 with a translated decreased 
demand distribution (demand shocks decreased by $c_{q}$ ) but without any holding or production costs; we just mark up its associated price by the marginal production cost. Because both strategies are analytically equivalent, we will focus in the remainder of this section on the analysis of Strategy 1 where we will set $c=c_{K}+c_{q}+c_{h}$.

Firm value $V_{1}$ equals expected revenues $\mathrm{E} \pi(p, K)$ $=p \mathrm{E} \min \left(K,(\epsilon-p)^{+}\right)$minus all costs $c K$. The expected revenue function $\mathrm{E} \pi(p, K)$ is a weighted linear superposition of $\pi(p, K, \epsilon)$ with weight factor $f(\epsilon)$. For a given $K$ and a specific realization of $\epsilon$ (that is, a specific sample path), the revenue function $\pi(p$, $K, \epsilon)$ as a function of price $p$ has three possible shapes depending on the value of $\epsilon$ as shown in Figure 1 . Each $\pi(p, K, \epsilon)$ has a unique maximal $p(K, \epsilon)$ and is unimodal concave-convex in $p$ and concave in $K$. As a weighted linear superposition, the expected revenue function $\mathrm{E} \pi(p, K)$ may inherit some structural properties from $\pi(p, K, \epsilon)$.

Exampl es. First consider the deterministic problem, which serves as a good base case to study the effect of uncertainty. The optimal capacity-constrained price $p^{\operatorname{det}}(K)$ equals $\max \left\{1-K, \frac{1}{2}\right\}$, as directly follows from Figure 1. The associated price-optimized revenue function is concave: It equals $(1-K) K$ if $K<\frac{1}{2}$ and $\frac{1}{4}$ elsewhere. For a stochastic example, assume $\epsilon$ is exponentially distributed with $f(\epsilon)=e^{-\epsilon}$. Its expected revenue function is $\mathrm{E} \pi=p e^{-p}\left(1-e^{-K}\right)$ and, as shown in Figure 1, is unimodal and concave-convex with optimal capacity-constrained price $p^{\exp }(K)=1$. Its price-optimized revenue function $e^{-1}\left(1-e^{-K}\right)$ is concave increasing in K. Explicit calculations in Van Mieghem and Dada (1998, Appendix) show that the uniform and left-truncated normal distributions also have a unimodal expected revenue function $\mathrm{E} \pi(p, K)$ with unique capacity-constrained price $p(K)$.

The fact that $\mathrm{E} \pi(p, K)$ is not jointly concave for many distributions prevents simple conditions that guarantee the uniqueness of the optimal $(p, K)$ solution. A traditional approach (Mills 1959, Petruzzi and Dada 1999, Ha 1997) is to simply assume that $P\left(\Omega_{0}\right)$ $=0$, which ensures the uniqueness of the constrainedmonopoly price $p(K)$. In general, however, $P\left(\Omega_{0}\right)$ need not be zero and there appears to be no simple, general characterization of the class of distributions for which $p(K)$, let alone the solution $(p, K)$, is unique. ${ }^{3} \mathrm{We}$ know that a maximizing nonnegative solution $(p, K)$ exists because $V_{1}(K, p)$ is continuous, $V_{1}(0, p)=0$ and bounded by (16). Such a solution must solve the necessary first-order conditions and we can add a simple sufficiency condition and some comparative statics:

\footnotetext{
${ }^{3}$ A simple but restrictive sufficient condition is that $f(x)$ is nondecreasing (e.g., uniform; see Appendix).
}

Figure 1 The Sample Path of $\pi(p, K, \epsilon)$ as a Function of $p$ for Three Representative Values of $\epsilon$ : Low $\left(\epsilon_{1}\right)$, Medium $\left(\epsilon_{2}\right)$, and High $\left(\epsilon_{3}\right)$

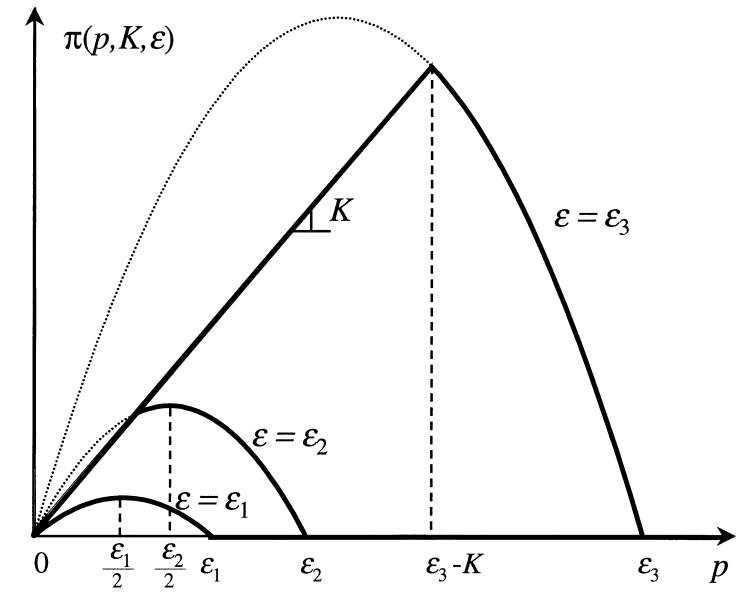

Note. On the right, we have $\mathrm{E} \pi(p, \mathrm{~K}, \epsilon)$ when $\epsilon$ is exponentially distributed.

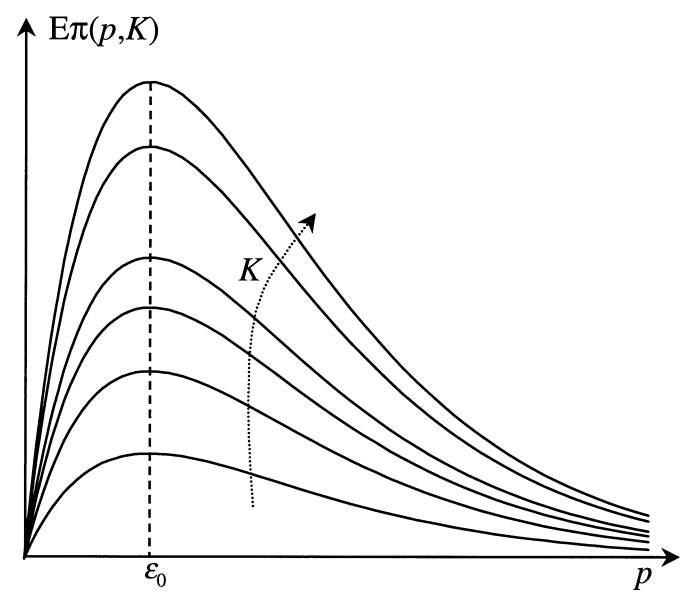

M anagement Science/Vol. 45, No. 12, December 1999 
Proposition 3. There exists a cost threshold $\bar{c}(\sigma)>0$ for the optimal solution $K$ and $p$ under Strategy 1: If $c$ $\geq \bar{c}(\sigma), K=0$ and $p$ is arbitrary, otherwise $K>0$ and $p$ $>0$ satisfy:

$$
p P\left(\Omega_{2}(p, K)\right)=c=\frac{p}{K} \int_{\Omega_{1}(p, K)}(2 p-\epsilon) d P
$$

and the optimal firm value $V_{1}$ and $K_{1}$ are decreasing in capacity costs $\left(d V_{1} / d c=-K\right)$ while $\operatorname{sign}(d p / d c)$ $=\operatorname{sign}(p h(p+K)-1)$. If, in addition, the hazard rate satisfies $h(p) \leq 1 / p \leq 2 / p \leq h(p+K)$, then conditions (20) are sufficient and the optimal price is increasing in $c$.

Notice that the hazard rate conditions require that the distribution is locally IFR (increasing failure rate) at the optimal $p$ and $K$. The proposition shows that under the optimal Strategy 1 there will always be a positive probability of having insufficient capacity leading to lost sales $\left(0<P\left(\Omega_{2}\right)=c / p<1\right)$, and of having excess capacity $\left(0<P\left(\Omega_{1}\right) \leq 1-P\left(\Omega_{2}\right)<1\right)$. While this is the familiar result of the newsvendor model, we will show in the next section that this is not true when the firm follows any of the price postponement Strategies 3, 4, or 5. The fact that firm value and capacity levels $K$ are decreasing in marginal investment costs, while $p$ is increasing, is not surprising. Because $\mathrm{E} \pi(p, K)$ is concave nondecreasing in $K$ while costs $C(K)=c K$ are convex increasing, the optimal investment strategy follows a critical number $\bar{c}$ policy, which can be evaluated at the optimal capacityconstrained price $p(K)$ if $\mathrm{E} \pi(p(K), K)$ inherits the concavity property:

$$
\bar{c}=\left.\frac{d}{d K} \mathrm{E} \pi(p(K), K)\right|_{K=0} .
$$

Examples. The deterministic base-case has a threshold cost $\bar{c}=\left.(1-2 K)\right|_{K=0}=1$ and if $c<1$ :

$$
\begin{gathered}
K^{\operatorname{det}}=\frac{1-c}{2}, \quad p^{\operatorname{det}}=\frac{1+c}{2} \text { and } \\
V^{\text {det }}=\frac{(1-c)^{2}}{4} \leq \frac{1}{4} .
\end{gathered}
$$

More interesting is the effect of uncertainty. As a start, exponential uncertainty has a threshold $\bar{c}=\left.e^{-(1+K)}\right|_{K=0}$ $=e^{-1}$ and if $c<e^{-1}$ :

$$
\begin{gathered}
K^{\exp }=-(1+\ln c), \quad p^{\exp }=1 \quad \text { and } \\
V^{\exp }=e^{-1}+c \ln c \leq e^{-1} .
\end{gathered}
$$

With exponential uncertainty, the monopolist charges a price $p=1$ independent of the investment cost. This price includes a mark-up of $(1-c) / 2$ compared to the deterministic monopoly price of $(1+c) / 2$. Interestingly, this mark-up is decreasing in cost, perhaps because the total exposure to uncertainty has decreased ( $K$ is decreasing in cost).

While the elegant explicit solutions for the exponential distribution give us some first insights into the effects of variability on price and capacity, this single-parameter distribution has the disadvantage that we cannot change the level of variability. Analytic comparative statics on the first order optimality equations as a function of variability yield very complex equations that cannot be signed in general. Therefore, we explicitly solved the capacity-pricing problem for the family of uniform distributions with mean $\epsilon_{0}=1$ and appropriately chosen standard deviation $\sigma$ to investigate the impact of various levels of variability on the pricing and investment decisions (explicit results are reported in Van Mieghem and Dada 1998, Appendix). Because $\epsilon$ is nonnegative, the support interval $\left[\boldsymbol{\epsilon}_{0}-\sqrt{3} \sigma, \boldsymbol{\epsilon}_{0}\right.$ $+\sqrt{3} \sigma]$ and its relative amount of variability as measured by the coefficient of variation are bounded when distributed uniformly: $\sigma / \epsilon_{0} \leq 3^{-1 / 2}$. For comparison, the one-parameter exponential distribution has coefficient of variation $\sigma / \epsilon_{0}=1$.

Figure 2 shows the optimal monopoly capacity investment, price, and firm value under strategy 1 assuming uniform and exponential uncertainty. We highlight three findings. First, the threshold $\bar{c}$ is decreasing in the level of variability $\sigma$ : As uncertainty increases, the firm requires a larger cost break before it is willing to invest. Second, the optimal solution $(p, K)$ is not monotone in variability $\sigma$. While for moderate and high capacity costs $c$ the investment level $K$ decreases as variability increases, the reverse is true for low capacity costs: Capacity is so inexpensive that 
Figure 2 The Optimal Monopoly Capacity $K$, Price $p$, and Firm Value V as a Function of the Marginal Cost $c=c_{k}+c_{q}+c_{h}$ and Variability (As Measured by the Coefficient of Variation $\sigma / \epsilon_{0}$ ) Under the No Postponement Strategy 1
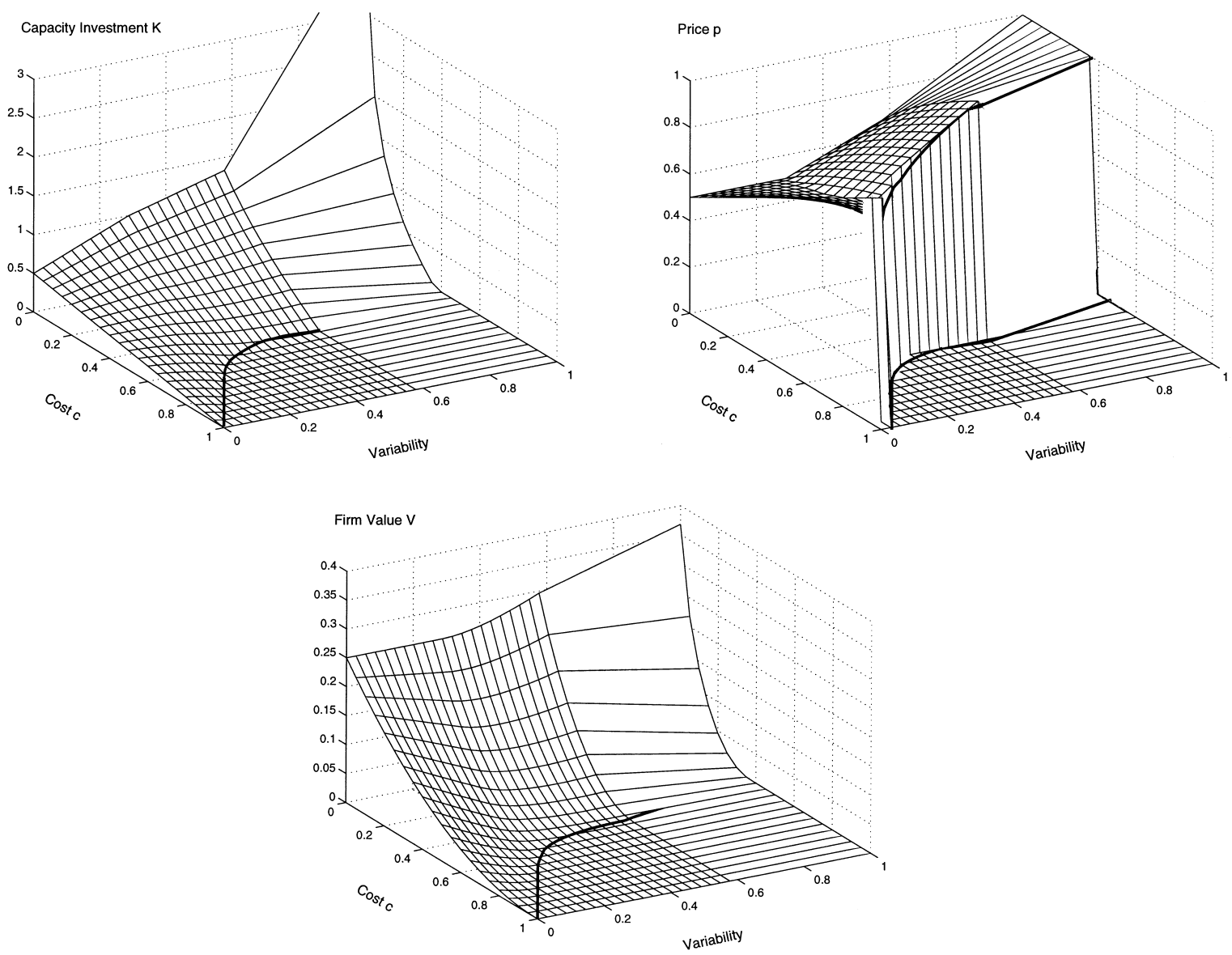

Note. The cost threshold $c(\sigma)$ is in bold.

Capacity Investment K: top left

Price p: top right

Firm Value V: bottom

one invests in more excess capacity as variability increases. Similarly, the optimal price is below the deterministic price for low variability levels, while it is increasing in variability for high variability levels. From a technical perspective, our analysis highlights the role of, and the added complication due to, the zero demand outcome $\Omega_{0}$. Disregarding the possibility of $\Omega_{0}$ as in the classical analysis of Mills (1959) leads to his well-known result that the optimal price under uncertainty is below the corresponding deterministic price. This, however, requires relatively modest variability and distributions that are bounded from below.
Otherwise, there is a positive probability that there is zero demand in some states $\left(P\left(\Omega_{0}\right)>0\right)$, in which case the optimal price can be higher than the deterministic price. Third, uncertainty does not necessarily result in decreased expected capacity-constrained revenues. Indeed, increased variability increases revenues for high capacity levels. Effectively, the demand distribution is censored and the effective mean demand and associated mean revenues are thus increasing in variability. (Domain $\Omega_{0}$ censors demand to zero, while in domains $\Omega_{1+2}$ the conditional mean demand is increasing in variability.) 


\section{Analysis of Price Postponement Strategies 3, 4, and 5}

Instead of setting price and capacity ex-ante (Strategies 1 and 2), the firm now sets production quantity and capacity (Strategies 3 and 4) or only capacity (Strategy 5) before uncertainty is realized. These quantity setting problems are significantly easier to analyze than price setting problems because their expected firm values are univariate. The optimal investment level $K_{i}$ under strategy $i$ solves the necessary firstorder condition $d V_{i}(K) / d K=0$, where

$$
\begin{aligned}
& \frac{d}{d K} V_{3}(K)=\int_{\Omega_{1+2}(K)}(\epsilon-2 K) d P-\left(c_{K}+c_{q}+c_{h}\right), \\
& \frac{d}{d K} V_{4}(K)=\int_{\Omega_{1+2(2 K)}}(\epsilon-2 K) d P-\left(c_{K}+c_{q}+c_{h}\right), \\
& \frac{d}{d K} V_{5}(K)=\int_{\Omega_{1+2}\left(c_{q}+2 K\right)}\left(\epsilon-2 K-c_{q}\right) d P-c_{K} .
\end{aligned}
$$

To unify the analysis of the strategies $i=3,4$, and 5 (and of the competitive strategies later), it is useful to first introduce the series of functions $k_{n}(\cdot)$ and some of its properties. The definition of $k_{1}$ exactly expresses the first order condition of $V_{3}$, while those of $k_{n}$ will express conditions under $n$-firm competition and $k$ $=k_{\infty}$ is equivalent to the first-order conditions of $V_{4}$ and $V_{5}$.

Definition 1. Each term in the series of functions $k_{n}(c)$, where $n \in \mathbb{N}$ and $c \in \mathbb{R}_{+}$, is defined as the smallest positive solution of $g_{n}(x)=c$ if $c<1$, where

$$
g_{n}(x)=\int_{\Omega_{1+2}(x)}\left(\epsilon-\frac{n+1}{n} x\right) d P,
$$

and $k_{n}(c)=0$ if $c \geq 1$.

Lemma 1. If the hazard rate is appropriately bounded in the sense that $h(x)-(n+1) / x$ has at most one zero and $\lim _{x 20} x h(x)<n+1$, then $g_{n}(x)=c$ has a unique positive solution for $c<1$. In general, the series is increasing:

$$
k_{1} \leq k_{2} \leq \cdots \leq k_{n} \leq \cdots \leq k_{\infty}=k \text {, }
$$

and

$$
\begin{gathered}
\frac{d}{d c} k_{n}(c) \leq-\frac{n}{n+1} \text { and } \\
k_{n}^{\operatorname{det}}(c)=\frac{n}{n+1}(1-c) \leq k_{n}(c) \leq \frac{n}{n+1} k(c) .
\end{gathered}
$$

The hazard rate condition characterizes a large class of distributions, which includes all increasing failure rate (IFR) distributions (because then $h(x)-(n$ $+1) / x$ is monotone and $h(0)$ finite) as well as not-too-strongly decreasing failure rate (DFR) distributions. Clearly, $k=k_{\infty}$ is always unique, regardless of the distribution.

Exa mpl es. For the deterministic base case, we have

$$
k_{n}^{\operatorname{det}}(c)=\frac{n}{n+1}(1-c) \mathrm{m} k^{\operatorname{det}}(c)=1-c .
$$

If $\epsilon$ is exponentially distributed, then $k_{n}$ is the unique positive solution to $e^{-k_{n}}\left(1-k_{n} / n\right)=c$. If $\epsilon$ is uniformly distributed over the interval $[1-\sqrt{3} \sigma, 1$ $+\sqrt{3} \sigma],(28)$ holds under moderate uncertainty $(\sqrt{3}$ $\sigma \leq(1+n c) /(1+n))$ so that $k_{n}=k_{n}^{\text {det }}$, otherwise $((1$ $+n c) /(1+n) \leq \sqrt{3} \sigma \leq 1)$ :

$$
\begin{aligned}
& k_{n}=\frac{1+\sqrt{3} \sigma}{2+n}\left(1+n-\sqrt{1+\frac{4 \sqrt{3} n(n+2) c \sigma}{(1+\sqrt{3} \sigma)^{2}}}\right) \\
& \mathrm{m} k=1+\sqrt{3} \sigma-2 \sqrt{\sqrt{3} \sigma c} .
\end{aligned}
$$

This example shows that if $\epsilon$ is bounded from below with probability one by $\epsilon$ and if $c$ is not too small so that $k_{n}<\underline{\epsilon}$ and thus $P\left(\Omega_{1+2}\left(k_{n}\right)\right)=1$, then $\epsilon$ "integrates out" and $k_{n}$ equals the deterministic solution $k_{n}^{\mathrm{det}}(c)=(n /(n+1))(1-c)$. Formally:

Lemma 2 (Uncertainty Insensitivity). If $\epsilon$ is bounded from below with probability one by $\underline{\epsilon}$ and capacity is not too inexpensive $c \geq 1-((n+1) / n) \underline{\epsilon}$, then $k_{n}$ is independent of variability and equal to the deterministic $k_{n}^{\text {det }}=$ $(n /(n+1))(1-c)$.

The lemmas show that $k_{1} \leq \frac{1}{2} k$ and $k\left(c_{K}+c_{q}+c_{h}\right)$ $\leq k\left(c_{K}\right)-c_{q}-c_{h}$ so:

Proposition 4. If the failure rate $h$ satisfies the condi- 
tion in Lemma 1, then the value functions $V_{i}(K)$ of strategy $i=3,4$, and 5 are unimodal and the associated unique optimal capacity levels $K_{i}$ rank as:

$$
\begin{gathered}
q_{3}=K_{3}=k_{1}\left(c_{K}+c_{q}+c_{h}\right) \leq q_{4}=K_{4}=\frac{1}{2} k\left(c_{K}+c_{q}+c_{h}\right) \\
\leq K_{5}=\frac{1}{2}\left(k\left(c_{K}\right)-c_{q}\right), \quad(29)
\end{gathered}
$$

where $k=k_{\infty}$. The optimal investment levels and firm values are decreasing in $c_{K}: \partial K_{i} / \partial c_{K}<0, \partial V_{i} / \partial c_{K}$ $=-K_{i}<0$ and, evaluating $k_{1}$ and $k$ at the costs as in (29):

$$
\begin{aligned}
V_{3} & =k_{1}^{2} \bar{F}\left(k_{1}\right) \leq V_{4}=\frac{1}{4}\left(\int_{0}^{k} \epsilon^{2} d F+k^{2} \bar{F}(k)\right) \\
& \leq V_{5}=\frac{1}{4}\left(\int_{c_{q}}^{k}\left(\epsilon-c_{q}\right)^{2} d F+\left(k-c_{q}\right)^{2} \bar{F}(k)\right) .
\end{aligned}
$$

(Notice that if $h(x)<(n+1) / x$, then $V_{i}$ is strict concave, a more stringent property than unimodality.) Thus, there exists a clear ranking among the price postponing Strategies 3, 4, and 5: The monopolist finds it optimal to increase investment as it has more ex-post flexibility in price and/or production (inventory) decisions. It is somewhat surprising that this is provable for such a large class of distributions. More importantly, it leads to a crucial distinction between information and uncertainty if one has ex-post price flexibility: Better information (in the sense that one observes $\epsilon$ earlier and has ex-post flexibility) actually increases capacity and production/inventory levels, so that both are complements. This, however, does not go against conventional wisdom in terms of safety stocks: More uncertainty (or worse ex-ante information in the sense of high variability in the ex-ante forecast of $\epsilon$ ) still induces the firm to carry capacity and production/inventory levels above the deterministic level. Indeed, by Lemma 1, the optimal price postponement capacity levels are never lower than under certainty:

$$
\begin{gathered}
\frac{1}{2}\left(1-c_{K}-c_{q}-c_{h}\right) \leq K_{3} \leq K_{4} \text { and } \\
\frac{1}{2}\left(1-c_{K}-c_{q}\right) \leq K_{5} .
\end{gathered}
$$

The proposition yields additional interesting facts. The uncertainty-insensitivity lemma applies to all price postponement strategies so that under moderate variability the equality sign holds in (31). Contrary to intuition, more postponement increases the sensitivity to uncertainty: The investment level under Strategy 5 is more sensitive to variability than under Strategy 4, which is more sensitive than under Strategy 3. Indeed, Lemma 2 yields that $K_{3}$ equals the deterministic solution if $P\left(\epsilon<k_{1}^{\mathrm{det}}=\frac{1}{2}\left(1-c_{K}-c_{q}-c_{h}\right)\right)=0$, which is less stringent to variability than $P\left(\epsilon<k^{\text {det }}=\right.$ $\left.1-c_{K}-c_{q}-c_{h}\right)=0$, the condition for $K_{4}$ to equal the deterministic solution. Similarly, $K_{5}$ equals its deterministic solution if $P\left(\epsilon<k^{\text {det }}=1-c_{K}\right)=0$. Thus, while more postponement increases value, it also increases sensitivity to uncertainty.

For example, insensitivity under the uniform distribution with $\underline{\epsilon}=1-\sqrt{3} \sigma$ requires $2 \sqrt{3} \sigma \leq c_{K}+c_{q}$ $+c_{h}+1, \sqrt{3} \sigma \leq c_{K}+c_{q}+c_{h}$ and $\sqrt{3} \sigma \leq c_{K}$, for Strategies 3,4 , and 5 , respectively. Thus, moderate levels of uncertainty $(\sigma \leq 1 / 2 \sqrt{3})$ never impact the capacity investment under Strategy 3. (While its optimal expected value of $V_{3}$ equals the deterministic value $\frac{1}{4}(1-c)^{2}$, the value obviously exhibits variability with standard deviation $\sigma_{V_{3}}=K_{3} \sigma_{\epsilon}$.) Higher variability levels or more postponement requires higher marginal costs for capacity decisions to remain insensitive. Notice that this insensitivity result never holds for the ex-ante price setting strategies 1 and 2 analyzed in the previous section.

Also, if variability is moderate in the sense that $P(\epsilon$ $\left.<\frac{1}{2}\left(1-c_{K}-c_{q}-c_{h}\right)\right)=0$ (or $\sqrt{3} \sigma \leq c_{K}+c_{q}+c_{h}$ under uniform uncertainty), then the simple price postponement strategy 3 equals the more refined Strategy 4 . Because there is zero probability of zero market-clearing price $\left(P\left(\Omega_{0}\left(K^{\mathrm{det}}\right)\right)=0\right)$ and the probability of "smarter" pricing is zero $\left(P\left(\Omega_{0}\left(2 K^{\text {det }}\right)\right)=0\right)$, the optimal ex-post price equals the market-clearing price. If, in addition holding costs are insignificant, price and production postponement (Strategy 5) is equivalent to Strategies 3 and 4 . This formally proves and quantifies the intuition that under moderate variability there is no incremental value to holding back output or postponing production, or equivalently, to receiving more timely information. Moreover, this shows that the value of additional production postponement may be relatively low if one can reduce 
demand uncertainty (through market demand management, for example) so that $V_{5}=V_{4}=V_{3}$.

Finally, price postponement strategies have a cost threshold $\bar{c}=1$ that is independent of demand variability because $k_{n}$ is positive if $c<1$ and zero otherwise. With uniform uncertainty, the cost threshold under no or production postponement decreases as demand becomes more variable (\$2). Hence, with uniform as with exponential uncertainty a price postponing monopolist is willing to invest at higher costs than a no postponement Strategy 1 monopolist. In addition, the investment differs: it is lower at low costs and higher at high cost as is evident from comparing Figures 2 and 3. Only in the deterministic limit $\left(\begin{array}{lll}\sigma & 0\end{array}\right)$ does the classical economics result that price and quantity setting give the same outcome hold. Figure 3 shows the optimal monopoly capacity investment and firm value for the simple price postponement Strategy 3 assuming uniform and exponential uncertainty. In the zone $c+1 \geq 2 \sqrt{3} \sigma$ of low variability levels or high costs, the capacity investment level and firm value are independent of variability and equal to their deterministic values. For higher levels of variability, both the capacity level and firm value increase. (Effectively, demand distribution truncation, analogous to that discussed in the previous section, occurs and the effective mean demand is increasing in variability.)

\section{Price Postponement Strategies Under Competition}

\subsection{Competitive Price Postponement Model}

When firms compete in a deterministic setting, Kreps and Scheinkman have identified conditions under which the production postponement (Bertrand price competition) and price postponement (Cournot quantity competition) investment decisions coincide. Unfortunately, in the presence of uncertainty the production postponement model is not well posed as Hviid (1991) showed that no pure strategy equilibria exist under stochastic price competition. We will show next that under uncertainty the simultaneous price postponement duopoly in the competitive version of our Strategies $3,4,5$, and 6 does have a pure equilibrium strategy. Then, we will generalize to oligopoly and perfect competition, and conclude with the value of different price postponement strategies under competition.

In competitive models one must specify the timing and nature of the observability of competitors' actions, in addition to uncertainty. Consider, for example, the $n$-firm competitive version of the price postponement Strategies 3 (§2). First, each firm $i$ simultaneously invests in capacity $K_{i}$. Then, investment levels $K$ are observed by all players and each firm $i$ simultaneously

Figure 3 The Optimal Monopoly Capacity K (Left) and Firm Value V (Right) as a Function of the Marginal Cost $\mathrm{c}=\mathrm{C}_{\mathrm{K}}+\mathrm{C}_{\mathrm{q}}+\mathrm{C}_{\mathrm{h}}$ and Variability (As Measured by the Coefficient of Variation $\sigma / \epsilon_{0}$ ) Under the Price-Postponement Strategy 3
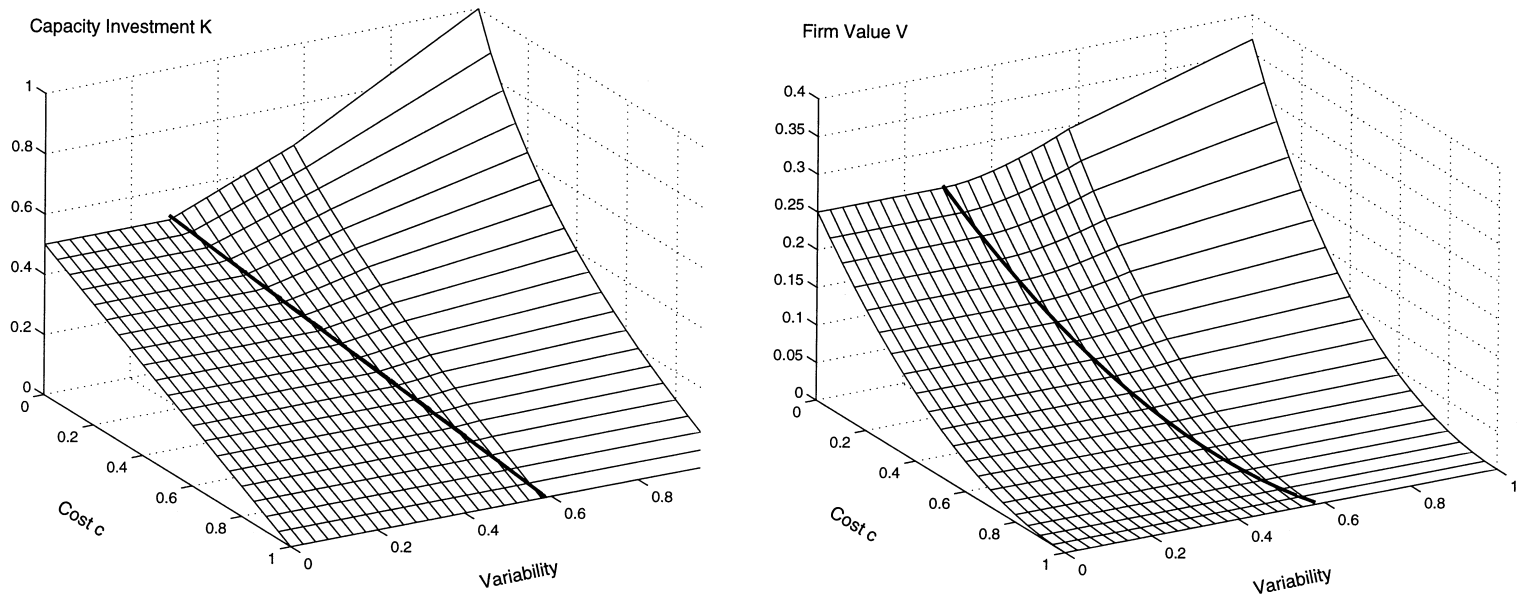

Note. The boundary of the uncertainty-insensitive zone $c+1 \geq 2 \sqrt{3} \sigma$ is in bold. 
announces the quantity $q_{i} \leq K_{i}$ that it will produce and bring to the market. Finally, uncertainty is resolved and the market mechanism determines the market clearing price $p=\epsilon-q_{+}$for the supplied market quantity $q_{+}=\sum q_{i}$. As in $\S 3$, this market clearing price is zero with oversupply $q_{+}>\epsilon$. (The competitive versions of Strategies 4,5 , and 6 are defined similarly.) All firms make their decisions to maximize expected profits, taking into account the other firm's likely decisions. Thus, we have a two stage noncooperative game that is solved by working backwards: First solve the capacity-constrained production subgame for a given capacity vector $K$, and then solve for the capacity decisions. Unlike under price competition, the revenue functions are continuous in the actions (i.e., in the quantities $q$ ) and a pure strategy equilibrium for the full price postponement game exists. We will start with the duopoly case and then extend to oligopoly.

5.1.1. The Capacity-Constrained Production Duopoly Subgame Under Strategy 3. Our question here is: Given capacity vector $K=\left(K_{1}, K_{2}\right)$, what are the (subgame perfect) production quantity decisions for both competitors under price postponement with clearance? Let $c=c_{q}+c_{h}$ denote the relevant marginal cost in this subgame. We will show that there exists a pure strategy equilibrium by showing that the firms' reaction curves intersect in a stable manner. Denote firm $i$ 's reaction function by $R_{i}(\cdot \mid K)$, where $q_{i}=R_{i}\left(q_{j} \mid K\right)$ denotes firm $i$ 's optimal quantity response when firm $j$ chooses quantity $q_{j}$, with associated first order conditions (FOC) for an interior unconstrained maximum:

$R_{i}\left(q_{j} \mid K\right)=\arg \max _{0 \leq q_{i} \leq K_{i}} \int_{q_{i}+q_{j}}^{\infty}\left(\epsilon-q_{i}-q_{j}\right) q_{i} f(\epsilon) d \epsilon-c q_{i}$

$$
\stackrel{\mathrm{FOC}}{\mathrm{f}} \int_{q_{i}+q_{j}}^{\infty}\left(\epsilon-2 q_{i}-q_{j}\right) f(\epsilon) d \epsilon=c .
$$

The strategy space of interest is the rectangle $\left[0, K_{1}\right] \times$ $\left[0, K_{2}\right]$ and the axis-crossings of $R_{i}(\cdot \mid K)$ can be specified in terms of the $k_{n}$ series evaluated at $c=c_{q}$ $+c_{h}$, as shown for a representative situation in Figure
4. In the appendix we show that $\left|\partial R_{i} / \partial q_{j}\right| \leq 1$ if the failure rate $h$ is appropriately bounded, so that both reaction curves intersect and a pure strategy equilibrium exists. The resulting unconstrained duopoly equilibrium is $\left(\frac{1}{2} k_{2}, \frac{1}{2} k_{2}\right)$, the symmetric intersection of the reaction curves if $K$ is large. If there is sufficient capacity, $K_{i}>k_{2}$, then $q(K)=k_{2}$, which is independent of the capacity vector $K$. Otherwise the equilibrium is on the intersection of a reaction curve with a constraint of the form $q_{i}=K_{i}$.

Proposition 5. If the hazard rate $h$ satisfies the condition of Lemma 1 and $h\left(k_{2}\right) \leq 2 / k_{2}$, then $q(K)$ $=\left(\frac{1}{2} k_{2}, \frac{1}{2} k_{2}\right)$ is a pure strategy subgame equilibrium for all $K>q(K)$ under price postponement. If, in addition, $h(x+y) \leq x^{-1}$ for all $0<x, y<k$, there exist a unique pure strategy equilibrium $q(K)$ for any capacity vector $K$, which is independent of $K_{i}$ if firm $i$ has excess capacity:

$$
\forall K_{i}>q_{i}(K): \frac{\partial}{\partial K_{i}} q(K)=0 .
$$

Compared to the monopoly, existence of a duopoly equilibrium requires only one additional condition on the hazard rate at the point $k_{2}$. Uniqueness of a competitive equilibrium is typically hard to prove;

Figure 4 Reaction Curves for Production Decisions when the Duopolists are Constrained by Capacity Vector $K$

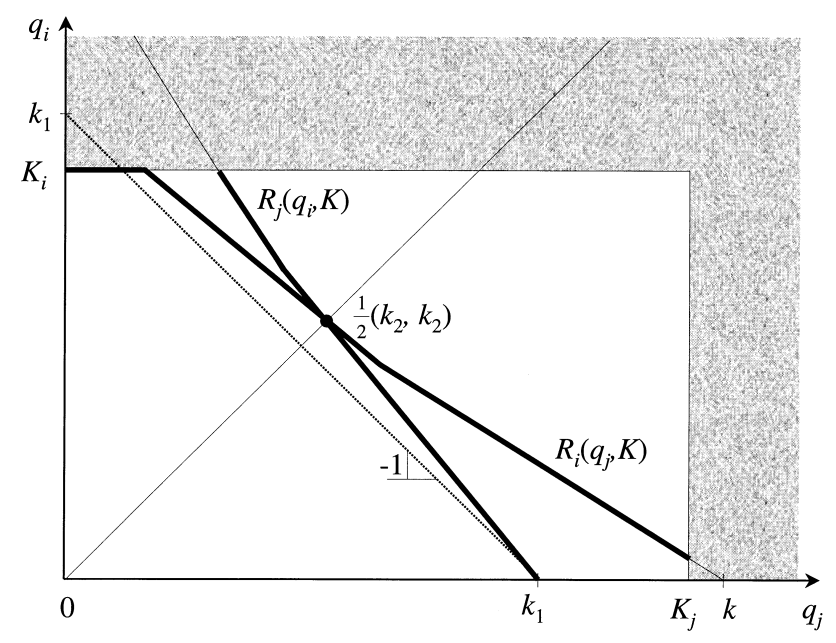

Note. All $k_{i}$ are evaluated at $c_{q}+c_{h}$ for Strategy 3 . 
surprisingly, it only involves a rather loose additional bound of $h(x)$ by $x^{-1}$ for small $x$.

Examples. For the deterministic example, the reaction curves are $R_{i}\left(q_{j} \mid K\right)=\min \left(\frac{1}{2}\left(1-q_{j}\right), K_{i}\right)$, with a unique solution (either interior at $q=\left(\frac{1}{3}, \frac{1}{3}\right)$ if $K \geq \frac{1}{3}$, or at the boundary $q_{i}=K_{i}$ or $q_{i}=K_{j}$ ). With exponential uncertainty, the reaction curves are trivial and have a unique intersection: $R_{i}\left(q_{j} \mid K\right)$ $=\min \left(1, K_{i}\right)$.

\subsubsection{The Price Postponement Full Game Under} Strategy 3. From Proposition 5, it follows that, similar to the monopoly case, any excess capacity level $K_{i}$ $>q_{i}(K)$ is a suboptimal investment $\left(\partial V_{i} / \partial K_{i}=-c_{K}\right.$ $<0$ ) provided both firms invest, in which case each will produce up to its capacity: $q=K$ and the relevant marginal cost becomes $c=c_{K}+c_{q}+c_{h}$. The capacity reaction curves become:

$$
\begin{aligned}
& \max _{0 \leq K_{i}} V_{i}(K)=\int_{K_{+}}^{\infty}\left(\epsilon-K_{+}\right) K_{i} f(\epsilon) d \epsilon-c K_{i} \\
& \underset{\mathrm{f}}{\mathrm{FOC}} \int_{K_{+}}^{\infty}\left(\epsilon-2 K_{i}-K_{j}\right) f(\epsilon) d \epsilon=c,
\end{aligned}
$$

where $K_{+}=\Sigma_{i} K_{i}$ denotes the total industry investment level. Clearly if $\partial V_{i} /\left.\partial K_{i}\right|_{K_{i}=0}=\int_{K_{j}}^{\infty}(\epsilon$ $\left.-K_{j}\right) f(\epsilon) d \epsilon-c<0$, firm $i$ will not invest. Thus, as before, there is a maximal cost-threshold $\bar{c}=\mathrm{E} \epsilon=1$, which is independent of uncertainty and above which no firm will invest. If capacity is not too expensive ( $c$ $<\bar{c})$, both firms invest $(K>0)$ and a similar argument as in the capacity-constrained production subgame shows that $K=\frac{1}{2}\left(k_{2}, k_{2}\right)$ is a symmetric duopoly equilibrium investment (which is unique under the additional condition of Proposition 5). The symmetric duopoly result directly generalizes to an oligopoly with $n$ firms (which may have additional equilibria):

Proposition 6. If the failure rate $h$ satisfies the condition of Lemma 1 and $h\left(k_{n}\right) \leq n / k_{n}$, then $q=K=0$ if $c$ $=c_{K}+c_{h}+c_{q}>1$ and, if $c \leq 1, q=K$ $=(1 / n)\left(k_{n}, \ldots, k_{n}\right)$ is a pure strategy n-oligopoly equilibrium under price postponement Strategy 3 with industry value $V_{+}^{(n \text { firms })}$ :

$$
\begin{aligned}
V_{+}^{(n \text { firms, Strategy 3) }} & =\frac{1}{n} k_{n}^{2} \bar{F}\left(k_{n}\right) \leq \frac{1}{n+1}(1-c) k_{n} \\
& \leq \frac{1}{n+1}(1-c) k .
\end{aligned}
$$

Exampl es. The duopoly capacity investment reaction curves for the deterministic reference case are $K_{i}\left(K_{j}\right)=\frac{1}{2}\left(1-K_{i}-c\right)$, with a unique interior equilibrium (for all $c<1) q_{i}=K_{i}=\frac{1}{3}(1-c)$ and $V_{i}$ $=\frac{1}{9}(1-c)^{2}$. With exponential uncertainty, the industry investment $K_{+}$solves $\left(1-\frac{1}{2} K_{+}\right) \exp \left(-K_{+}\right)=c$ for $c<\bar{c}=1$.

Three interesting insights follow from the oligopoly extension of the price postponing Strategy 3. First, the qualitative results of a price postponing monopoly extend to oligopolistic and perfect competition under uncertainty: The functional dependence on cost and uncertainty is similar to Figure 3. Second, Lemma 1 shows that the industry investment $K_{+}^{(n \text { firms })}=k_{n}$ is increasing in the industry size $n$ while industry firm values (or profits) are decreasing:

$$
\begin{aligned}
& K_{+}^{(n \text { firms })} \leq K_{+}^{(n+1 \text { firms })} \leq K_{+}^{\text {(perfect competition })}=k, \\
& V_{+}^{(n \text { firms })} \geq V_{+}^{(n+1 \text { firms })} \geq V_{+}^{(\text {perfect competition })}=0 .
\end{aligned}
$$

Not only is this in line with economic intuition, it also provides a nice interpretation of the reference investment $k$ that defined optimal monopoly capacity levels under the postponement strategies of $\S 4: k$ is the industry investment that would obtain under perfect competition. Thus, in the context of our model, a monopolist adopting the refined price postponement Strategy 4 invests in exactly half the perfect competition industry capacity. Third, the insensitivity result of Lemma 2 that price postponing firms under moderate levels of uncertainty invest exactly like deterministic firms remains valid, but is more subdued, in an oligopoly with $n$ firms. Indeed, the optimal industry investment $K_{+}^{(n \text { firms })}$ equals the deterministic investment $(n /(n+1))(1-c)$ if $(n /(n+1))(1-c)<\underline{\epsilon}$ (for the uniform distribution: $\sigma \leq(n c+1) /(n$ $+1) \sqrt{3})$. Oligopoly firms facing moderate levels of uncertainty $(\sigma \leq 1 /(n+1) \sqrt{3})$ invest exactly like deterministic firms regardless of the capacity $\operatorname{cost} c$. As competition intensity $n$ rises, however, uncertainty 
becomes more important because the insensitivity zone shrinks. Yet it never disappears: Insensitivity to uncertainty remains at higher levels of uncertainty and under perfect competition, provided capacity costs are high $(1>c>\sqrt{3} \sigma)$.

\subsection{The Sales Subgame in Competitive Postponement Strategies 4, 5, and 6}

The competitive analysis of Strategies 4, 5, and 6 involves an additional ex-post subgame where firms simultaneously bring a sales quantity $s$ to the market after observing $\epsilon$. This is a deterministic subgame with reaction curves of the form

$$
\begin{gathered}
R_{i}: \underset{s_{i} \leq q_{i}}{\arg \max }\left(\epsilon-s_{i}-\sum_{j \neq i} s_{j}\right) s_{i}-c s_{i} \\
\stackrel{\mathrm{FOC}}{\mathrm{F}} \epsilon-2 s_{i}-\sum_{j \neq i} s_{j}=c \quad \text { if } s_{i} \leq q_{i}
\end{gathered}
$$

where $c=0$ under Strategy 4 (production is sunk), $c$ $=c_{q}$ under Strategy 5 (ex-post production) and $c=c_{K}$ $+c_{q}$ under full postponement Strategy 6 . These reaction curves have a unique intersection (the determinant of the linear system equals $n+1>0$ ) so that:

Lemma 3. The sales subgame has a unique (unconstrained) equilibrium:

$$
s_{i}=\frac{(\epsilon-c)^{+}}{n+1} \text { and } p=\frac{\epsilon+n c}{n+1},
$$

which, together with $q_{i}=K_{i}=s_{i}$, is the unique equilibrium under total postponement Strategy 6 with corresponding value

$$
\begin{aligned}
& V_{i}(\epsilon)=\left(\frac{\epsilon-c}{n+1}\right)^{+2} \text { and } V_{+}^{(n \text { firms, Strategy } 6)}= \\
& \frac{n}{(n+1)^{2}} \mathrm{E}(\epsilon-c)^{+2} \leq V_{+}^{\text {det }}+\frac{n}{(n+1)^{2}} \sigma^{2} .
\end{aligned}
$$

Similar reasoning as before shows that under Strategy 4 each firm will set $q=K$ and again there exists a symmetric pure equilibrium that satisfies:

$$
\int_{(n+1) K_{i}}^{\infty}\left(\epsilon-(n+1) K_{i}\right) f(\epsilon) d \epsilon=c_{K}+c_{q}+c_{h},
$$

so that, using $k$ evaluated at $c=c_{K}+c_{q}+c_{h}$ :

$$
\begin{gathered}
K_{+}^{(n \text { firms, Strategy } 4)}=\frac{n}{n+1} k, \\
V_{+}^{(n \text { firms, Strategy 4) }}=\frac{n}{(n+1)^{2}}\left[\int_{0}^{k} \epsilon^{2} d F+k^{2} \bar{F}(k)\right] .
\end{gathered}
$$

Similarly, there exist a symmetric pure equilibrium for Strategy 5:

$$
\int_{(n+1) K_{i}+c_{q}}^{\infty}\left(\epsilon-(n+1) K_{i}-c_{q}\right) f(\epsilon) d \epsilon=c_{K},
$$

so that, again using $k$ but now evaluated at $c=c_{K}$ :

$$
K_{+}^{(n \text { firms, Strategy 5) }}=\frac{n}{n+1}\left(k-c_{q}\right),
$$

$$
\begin{aligned}
V_{+}^{\left(n \text { firms, Strategy 5) }=\frac{n}{(n+1)^{2}}\left[\int_{c_{q}}^{k}\left(\epsilon-c_{q}\right)^{2} d F\right.\right.} \\
\\
\left.\quad+\left(k-c_{q}\right)^{2} \bar{F}(k)\right] .
\end{aligned}
$$

\subsection{The Value of Postponement Under Competition}

Postponement and competition yield two additional interesting insights. First, postponement is clearly more profitable to the firm and justifies a higher investment (Corollary 1). In addition, the impact of uncertainty is higher under postponement and independent of competition intensity. Indeed, the insensitivity zone shrinks from $(n /(n+1))(1-c)<\underline{\epsilon}$ to 1 $-c<\underline{\epsilon}$. Second, the competitive model allows us to investigate the relative value to the firms of the postponement strategies as a function of competition intensity $n$. Figure 5 shows the value of price postponement $V_{3}$, the value of additional hold-back strategy $\left(V_{4}-V_{3}\right)$, and the value of total postponement $\left(V_{6}\right.$ $\left.-V_{4}\right)$ relative to the value of total postponement $\left(V_{6}\right.$ $=100 \%$ ) as a function of $n$. (While the results are shown for the uniform distribution with $\sigma=0.5$ with $c_{K}=0.4$ and $c_{h}=c_{q}=0$-thus, $V_{5}=V_{4}$, similar trends were observed for other parameter values.) The 


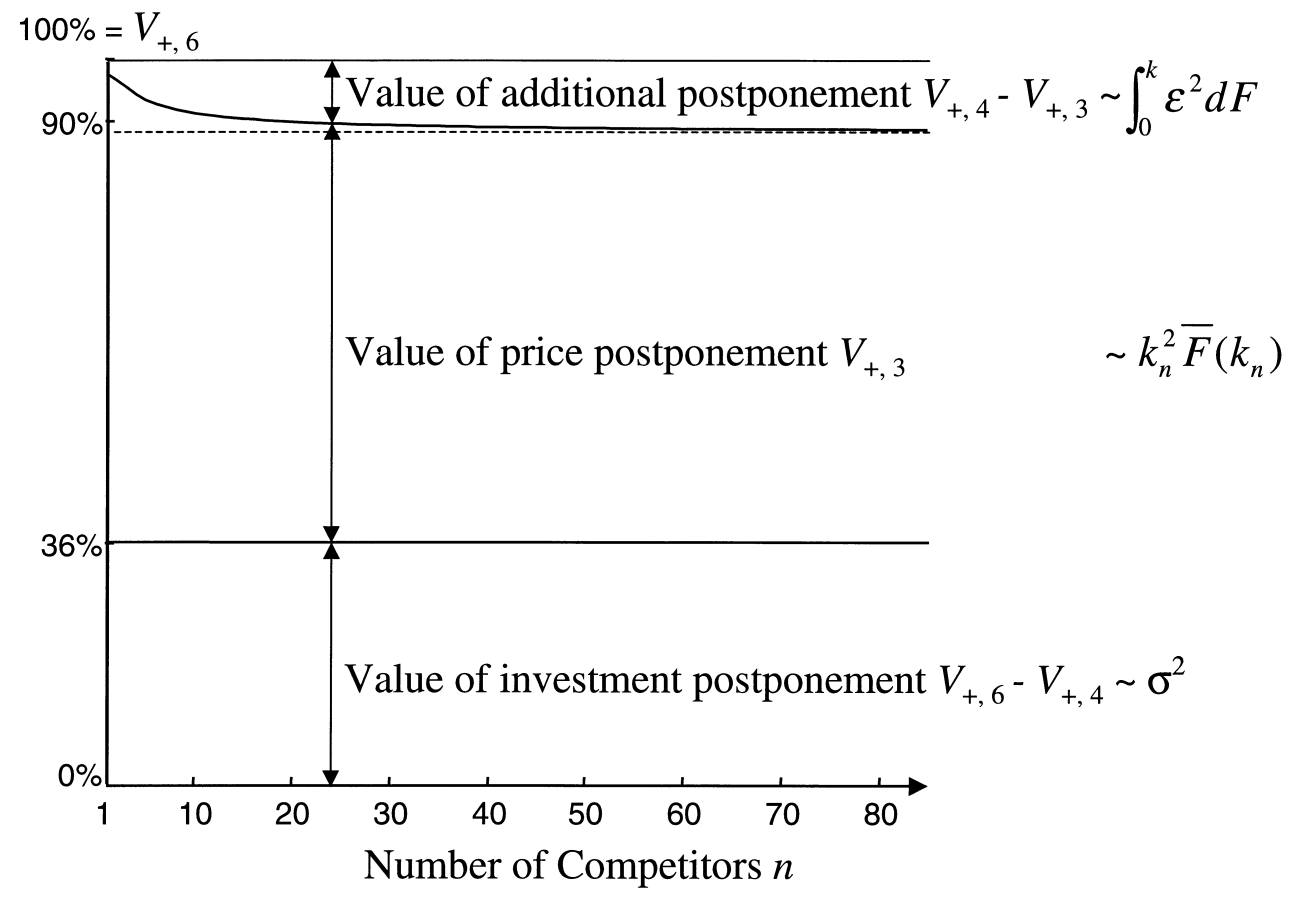

interesting observation is that the relative value to firms of operational techniques (hold-back and/or production postponement) on strategic decisions (investment) seems to increase as the industry becomes more competitive. Although the impact of additional postponement is only on the order of $10 \%$, this remains significant because postponement of production is the more realistic operational strategy and easier to implement than investment postponement.

\section{Concluding Remarks and Extensions}

In the introduction we presented several motivating examples. The analyses of the postponement strategies help us understand how postponement of different operational decisions may help in different markets. For instance, if uncertainty and investment costs are high it is possible for a no flexibility firm (Strategy 1), such as a mail-order company or a fashion goods manufacturer, to outperform a simple price postponement firm (Strategy 3), such as an unsophisticated retailer. In a full manufacturing context, however, production postponement Strategy 2 (which may model a simple make-to-order firm) is inherently harder to analyze than price postponement Strategy 3 (simple make-to-stock) and either strategy may be appropriate depending on the cost parameters and demand uncertainty. Actually, our analysis suggests that simple make-to-stock with price flexibility is preferred to simple make-to-order if variability levels and marginal production and holding costs are low. We should note that marginal manufacturing costs may increase under production postponement because of the faster response time that is required of the production process. In that case, the relative ranking of the various postponement strategies becomes more muddled, which may help explain why it can be economically efficient for these strategies to coexist in different environments.

While our model assumed a simple linear demand curve $p=\epsilon-D$ with "additive" uncertainty ( $\epsilon$ adds to price $p$ ), our price postponement results continue to 
hold for more general types of uncertainty and general demand curves of the form

$$
p=\epsilon_{1} g(D)+\epsilon_{2} h(D),
$$

where $g$ and $h$ are deterministic downward sloping functions and $\epsilon$ is a random (possible correlated) positive vector. The impact of "multiplicative uncertainty" ( $\epsilon$ multiplies price) in competition, however, remains to be studied. Some insight into how to analyze this difficult extension can be gleaned from Klemperer and Meyer (1986) who consider a closely related single stage model with price and production decisions (without capacity investment) where demand uncertainty has different types of shocks. Another welcome extension would be to consider postponement and competition in a dynamic, multi-period model. Useful starting points may be the multi-period monopoly models of Amihud and Mendelson (1983a, b), Federgruen and Heching (1999), Gallego and van Ryzin (1984) and Li (1988). Finally, it may be interesting to incorporate the option to ex-post buy additional capacity (at a higher cost than $c_{K}$ ) or sell excess capacity. Having two capacity decision epochs will improve performance and decrease the value of operational postponement. ${ }^{4}$

\footnotetext{
${ }^{4}$ We greatly benefitted from the suggestions of the anonymous referees and the associate editor and from the comments of seminar participants at INSEAD, University KU Leuven, Northwestern University and Stanford University.
}

\section{Appendix}

Proof of Proposition 2. Follows directly from the fact that $p_{2}$ $>c_{q}$ and a change of integration variable $\epsilon=\epsilon^{*}+c_{q}$ in (7).

Proof of Proposition 3. The necessary first-order conditions of $V_{1}$ are (20). Because $\partial^{2} V / \partial K^{2}=-p f(p+K) \leq 0, V_{1}$ is concave in $K$ and the sufficient conditions only involve $\partial^{2} V / \partial p^{2}$ and the Hessian $H$ :

$$
\begin{aligned}
\frac{\partial^{2} V}{\partial p^{2}} & =p f(p)+2 F(p)-p f(p+K)-2 F(p+K) \\
& =[p h(p)-2] \bar{F}(p)-[p h(p+K)-2] \bar{F}(p+K) \leq 0, \\
\operatorname{det}(H) & =p f(p+K)[2 \bar{F}(p)-p f(p)]-[\bar{F}(p+K)]^{2} \geq 0 \\
& \mathrm{~N} p h(p+K)[2-p h(p)] \geq \bar{F}(p) \bar{F}(p+K) .
\end{aligned}
$$

Clearly, both conditions are satisfied if $p h(p+K) \geq 2$ and $p h(p)$ $\leq 1$. (Notice that $V_{1}$ is concave in $p$ if $f$ is nondecreasing, or if $P\left(\Omega_{0}\right)$
$=0$ so that $f(p)=F(p)=0$.) Implicit differentiation of the first-order conditions w.r.t. $c$, yields

$$
\begin{gathered}
\operatorname{det}(H) \frac{\partial K}{\partial c}=\frac{\partial^{2} V}{\partial p^{2}} \text { and } \\
\operatorname{det}(H) \frac{\partial p}{\partial c}=-\frac{\partial^{2} V}{\partial p \partial K}=p f(p+K)-\bar{F}(p+K),
\end{gathered}
$$

so that $\partial p / \partial c>0$ if $p h(p+K) \geq 1$.

Proof of Lemma 1. A positive root to $g_{n}(x)=c$ always exists if 0 $<c<1$ by Weierstrass' theorem because $g_{n}$ is continuous with $g_{n}(0)$ $=\mathrm{E} \epsilon=1$ and $g_{n}(\infty)=0$ (because $\epsilon$ is finite with probability one so that $F$ is a real distribution with $x \bar{F}(x) 30$ as $x 3 \infty)$. Because

$$
g_{n}^{\prime}(x)=\frac{1}{n} x f(x)-\frac{n+1}{n} \bar{F}(x) \geq-\frac{n+1}{n},
$$

$g_{n}(x) \geq 1-((n+1) / n) x$ and $k_{n} \geq(n /(n+1))(1-c)$. Because $g_{n}(0)=1$ and $g_{n}^{\prime}(0)<0$ if $\lim _{x 20} x h(x)<n+1, g_{n}$ is initially decreasing (and thus $V_{i}$ concave increasing). If $x f(x)-(n+1) \bar{F}(x)$ has at most one zero $x_{n}^{*}$, then $g_{n}$ has at most one minimum $x_{n}^{*}$ for which $g_{n}^{\prime}(x)<0$ for $x<x_{n}^{*}, g_{n}^{\prime}(x)>0$ for $x>x_{n}^{*}$ and $g_{n}(x)<0$ for $x \geq x_{n}^{*}$, because $g_{n}(\infty)=0$, so that $V_{i}$ is unimodal concaveconvex. Hence, the root $k_{n}(c)$ is unique in that case and $k_{n}(c)<x_{n}^{*}$; otherwise define $k_{n}$ as smallest positive root. Then, $g_{n}$ is decreasing at $k_{n}$ so $-(n+1) / n \leq g_{n}^{\prime}\left(k_{n}(c)\right) \leq 0$ so that $k_{n}^{\prime}(c)=1 / g_{n}^{\prime}\left(k_{n}(c)\right)$ $\leq-n /(n+1)$. Because $g_{n}(x)$ is increasing in $n$ we have that the series $k_{n}$ is increasing. Last, $g_{n}(x)<g_{\infty}(((n+1) / n) x)$ because the integrand of $g_{n}$ is negative for $\epsilon<((n+1) / n) k_{n}$. Because $g_{\infty}(x)$ is monotone decreasing $\left(g_{\infty}^{\prime}(x)=-\bar{F}(x) \leq 0\right), k=k_{\infty}$ is always unique and $((n+1) / n) k_{n} \leq k$.

Proof of Proposition 5. First assume that $K_{i}>k_{1}$ is large such that player $i$ has an unconstrained optimal quantity $q_{i}<K_{i}$. The reaction curve $q_{i}=R_{i}\left(q_{j} \mid K\right)$ solves the FOC shown in (32) and has second order condition SOC: $q_{i} f\left(q_{+}\right)-2 \bar{F}\left(q_{+}\right)<0$. Applying the implicit function theorem to the FOC yields

$$
\frac{\partial q_{i}\left(q_{j}\right)}{\partial q_{j}}=-\frac{\bar{F}\left(q_{+}\right)-q_{i} f\left(q_{+}\right)}{2 \bar{F}\left(q_{+}\right)-q_{i} f\left(q_{+}\right)}=-\frac{1-q_{i} h\left(q_{+}\right)}{2-q_{i} h\left(q_{+}\right)},
$$

so that if $q_{i} h\left(q_{+}\right) \leq 1$ for all $q_{i}<k_{n-1}$ and $q_{j}<k$, we have that -1 $\leq \partial q_{i}\left(q_{j}\right) / \partial q_{j} \leq 0$ (this remains valid for an oligopoly game with $n$ firms). If $K_{j}>k_{1}$ is also large with interior optimum, its reaction curve is also decreasing with slope $\leq-1$. Thus, the two unconstrained reaction curves have exactly one intersection and that equilibrium is symmetric (hence, $q_{i}=\frac{1}{2} q_{+}$and $q_{+}=k_{2}$ ) and equals the unique point $\left(\frac{1}{2} k_{2}, \frac{1}{2} k_{2}\right)$. Existence of this point only requires that $k_{2}$ exists (Lemma 1: $k_{2} h\left(k_{2}\right)<3$, guaranteeing the SOC) and is locally stable $\left(k_{2} h\left(k_{2}\right)<2\right)$.

If $K_{i}$ is small $\left(K_{i}<k_{1}\right)$, the response function $q_{i}\left(q_{j}\right)$ is constant at $q_{i}=K_{i}$ for small $q_{j}$. After a certain value of $q_{j}$, the optimum coincides with the interior point $q_{i}\left(q_{j}\right)$ from before. Thus, if $K$ $\leq\left(\frac{1}{2} k_{2}, \frac{1}{2} k_{2}\right)$, the unique equilibrium is $q=K$ and if $K \geq\left(\frac{1}{2} k_{2}, \frac{1}{2} k_{2}\right)$, the unique equilibrium remains $\left(\frac{1}{2} k_{2}, \frac{1}{2} k_{2}\right)$. Thus, the only remaining case is that $K_{i}<\frac{1}{2} k_{2}<K_{j}$ (or its symmetric counterpart). Let $q_{c}$ 
denote the unique intersection of firm $j$ 's unconstrained reaction curve $q_{j}\left(q_{i}\right)$ with $q_{i}=K_{i}: q_{c}=q_{j}\left(K_{i}\right)$. It directly follows that $\frac{1}{2} k_{2}$ $\leq q_{c} \leq k_{1}$. Now, if $K_{j} \in\left(\frac{1}{2} k_{2}, q_{c}\right]$, the unique equilibrium is $q=K$; otherwise if $K_{j}>q_{c}$, the unique equilibrium is $q=\left(K_{i}, q_{c}\right)$. This also shows that if a firm has excess capacity $\left(\forall K_{i}>\right.$ the unique equilibrium $\left.q_{i}(K)\right)$ we have that $\partial q(K) / \partial K_{i}=0$. $\square$

\section{References}

Amihud, Y., H. Mendelson. 1983a. Multiperiod sales-production decisions under uncertainty. J. Econom. Dynamics and Control 5 249-265.

_ 1983 . Price smoothing and inventory. Rev. Econom. Stud. 50(160) 87-98.

Anand, K. S. 1999. Can information and inventories be complements? Technical report, Northwestern University, June.

- H. Mendelson. 1998. Postponement and information in a supply chain. Technical report, Northwestern University, July.

Andrews, E. L. 1999. DaimlerChrysler's smart car is lone sore spot at meeting. The New York Times May 19.

Anupindi, R., S. Chopra, S. D. Deshmukh, J. A. Van Mieghem, E. Zemel. 1999. Managing Business Process Flows, 1st ed. Prentice Hall, Upper Saddle River, NJ 07458.

Arthur, D. S. 1997. Optimal Capacities with Uncertainties and Applications to the Truckload Sector of the Motor Carrier Industry. Ph.D. Thesis, Field of Economics, Northwestern University, Evanston, IL.

Bashyam, T. 1996. Competitive capacity expansion under demand uncertainty. European J. Oper. Res. 95 89-114.

Butz, D. 1997. Vertical price controls with uncertain demand. J. Law and Econom. 40 433-459.

Deneckere, R., H. Marvel, J. Peck. 1996. Demand uncertainty, inventories and resale price maintenance. Quart. J. Econom. 111 885-913.

_,$\ldots$ - 1997. Demand uncertainty and price maintenance: Markdowns as destructive competition. Amer. Econom. Rev. 87 619-641.

_ J. Peck. 1995. Competition over price and service rate when demand is stochastic. Rand J. Econom. 26 148-162.

Federgruen, A., A. Heching. 1999. Combined pricing and inventory control under uncertainty. Oper. Res. 47(3) 454-475.

Gal-Or, E. 1987. First mover disadvantages with private information. Rev. Econom. Stud. 54 279-292.

Gallego, G., G. J. van Ryzin. 1994. Optimal dynamic pricing of inventories with stochastic demand over finite horizons. Management Sci. 40(8) 999-1020.
Ha, A. Y. 1997. Supply contract for a short-life-cycle product with demand uncertainty and asymmetric cost information. Technical report, Yale School of Management, New Haven, CT. May.

Hviid, M. 1990. Sequential capacity and price choices in a duopoly model with demand uncertainty. J. Econom. 51(2) 121-144.

—. 1991. Capacity constrained duopolies, uncertain demand and non-existence of pure strategy equilibria. European J. Political Econom. 7 183-190.

Klemperer, P., M. Meyer. 1986. Price competition vs. quantity competition: The role of uncertainty. Rand J. Econom. 17618 638.

Kreps, D., J. Scheinkman. 1983. Quantity precommitment and Bertrand competition yield Cournot outcomes. Bell J. Econom. 14 326-337.

Lee, H. L., C. S. Tang. 1998. Variability reduction through operations reversal. Management Sci. Feb. 162-172.

Li, L. 1988. A stochastic theory of the firm. Math. Oper. Res. 13(3) 447-466.

Lippman, S. A., K. F. McCardle. 1997. The competitive newsboy. Oper. Res. 45 54-65.

Mills, E. S. 1959. Uncertainty and price theory. Quart. J. Econom. 73 116-130.

Padmanabhan, V., I. P. L. Png. 1997. Manufacturer's return policies and retail competition. Marketing Sci. 16(1) 81-94.

Parlar, M. 1988. Game theoretic analysis of the substitutable product inventory problem with random demand. Naval Res. Logist. 35 397-405.

Peck, J. 1996. Demand uncertainty, incomplete markets and the optimality of rationing. J. Econom. Theory 70 342-363.

Petruzzi, N. L., M. Dada. 1999. Pricing and the newsvendor model: A review with extensions. Oper. Res. 47(2) 183-194.

Signorelli, S., J. L. Heskett. 1984. Benetton (A) and (B). Harvard Business School Case, (9-685-014), Boston, MA. 1-20.

Van Mieghem, J. A. 1999. Coordinating investment, production and subcontracting. Management Sci. 45(7) 954-971.

— M. Mada. 1998. Price versus production postponement: Capacity and competition. Appendix with explicit results. Technical report, Center for Mathematical Studies in Economics and Management Science, Northwestern University, Evanston, IL. 1998. Available at http://www.kellogg.nwu.edu/research/ math.

Whitin, T. M. 1955. Inventory control and price theory. Management Sci. 2 61-68.

Accepted by Linda V. Green; received August 31, 1998. This paper has been with the authors 2 months for 1 revision. 